INTERVENTIONAL CARDIOLOGY AND SURGERY

\title{
Trends in two year risk of repeat revascularisation or death from cardiovascular disease after coronary artery bypass grafting or percutaneous coronary intervention in Western Australia, 1980-2001
}

\author{
K A McCaul, M S T Hobbs, M W Knuiman, J M Rankin, I Gilfillan
}

Heart 2004;90:1042-1046. doi: 10.1136/hrt.2003.022178

See end of article for authors' affiliations

..........

Correspondence to: A/Prof M S T Hobbs, School of Population Health, University of Western Australia, 35 Stirling Hwy, Crawley 6009, Western Australia Australia; mikeh@sph. uwa.edu.au

Accepted

28 November 2003

\begin{abstract}
Aims: To investigate whether, over the 21 year period 1980-2001, there had been a reduction in the risk of repeat revascularisation or death from cardiovascular disease in the cohort of all patients who were treated by coronary revascularisation in Western Australia.

Setting: State of Western Australia.

Patients: All patients treated by coronary artery bypass graffing $(C A B G)$ or percutaneous coronary intervention (PCI) between 1980 and 2001.

Design: Cohort study.

Main outcome measures: Risk of repeat coronary artery revascularisation procedures (CARP) and risk of death from cardiovascular disease after first CARP.

Results: After a CABG procedure, the two year risk of repeat revascularisation remained low (less than $2 \%$ ) across the period 1980-2001. For PCl, however, this risk declined significantly from $33.6 \%$ in $1985-$ 9 to $12.4 \%$ in $2000-1$. The risk of death from cardiovascular disease after a CARP declined by about $50 \%$ between 1985 and 2001.

Conclusions: Outcomes such as the risk of repeat revascularisation and the risk of death from cardiovascular disease have improved significantly for patients who underwent CARPs across the period 1980-2001. This has occurred despite an increasing trend in first CARP rates among older people and those with a recent history of myocardial infarction.
\end{abstract}

n 1980, 350 coronary artery revascularisation procedures (CARPs) were performed in Western Australia and all were performed in one major teaching hospital in Perth. Almost all $(99 \%)$ of these were coronary artery bypass graft (CABG) procedures and almost all (99\%) were first ever procedures. By 2001, CARP procedures were being performed in seven Perth metropolitan hospitals and, of the 3023 performed that year, only $1034(34.2 \%)$ were CABGs. The remainder were percutaneous coronary intervention (PCI) procedures, most $(93 \%)$ involving the use of coronary stents. A significant proportion of the CARPs performed in this year were repeat procedures (768 or 25.4\%). Between 1980 and 2001 the provision of CARPs increased significantly, particularly for PCI procedures such as balloon angioplasty (introduced in 1980) and coronary stenting (introduced in 1995). After 1992, rates of performance of CABGs declined as PCI procedures became the primary intervention. Overall, the increase in the performance of CARPs was most significant among patients aged 65 years or more. ${ }^{1}$

Comparisons of outcomes of CABG and PCI procedures have been the subject of several randomised controlled trials. ${ }^{2-7}$ While these have found similar risks of mortality after either procedure, the risk of repeat revascularisation was significantly higher after PCI procedures than after CABG procedures. Randomised controlled trials have also shown the efficacy of coronary stenting over PCI alone. ${ }^{8-12}$

While randomised controlled trials have strong internal validity, inclusion and exclusion criteria often restrict the population to which they remain externally valid. This is particularly so when the indications for surgical or percutaneous intervention change over time. Consequently, the more widespread application of treatments evaluated by randomised controlled trials may not produce the same results.

The aim of this study was to investigate whether, over the 21 year period 1980-2001, there had been a reduction in the risk of repeat revascularisation or death from cardiovascular disease (CVD) in the cohort of all patients who were treated by coronary revascularisation in Western Australia. Western Australia is ideally suited for this study because all major medical services are concentrated in the capital city, Perth, which is geographically isolated. The nearest major population centre outside of Perth is $1600 \mathrm{~km}$ away in the adjoining state and so the provision of medical treatment outside the state for any reason is rare. In addition, a population based health record linkage system exists within Western Australia and hence mortality records and all hospital admission records, from both public and private hospitals, are linked by probabilistic methods. ${ }^{13}$ This means that not only admissions for CARPs but also readmissions for repeat CARPs and the date and cause of death after a CARP can be identified.

\footnotetext{
Abbreviations: $A M I$, acute myocardial infarction; $C A B G$, coronary artery bypass grafting; $C A B R I$, coronary angioplasty versus bypass revascularisation investigation; CARPs, coronary artery revascularisation procedures; CVD, cardiovascular disease; GABI, German angioplasty bypass surgery investigation; ICD, International classification of diseases; ICD-9-CM, International classification of diseases, ninth revision, clinical modification; MONICA, monitoring trends and determinants in cardiovascular disease; $\mathrm{PCl}$, percutaneous coronary intervention; RITA, randomised intervention treatment of angina
} 


\section{METHODS}

\section{Data sources}

The study was based on the subset of the Western Australian Health Data Linkage System that contains electronic records of all hospital admissions or deaths from any form of CVD occurring in the period from 1979 to 2001 inclusive. Each record in the file contains a computer generated unique personal identifying number enabling the aggregation of records relating to individual patients. The file contained data for 423922 patients who had a diagnosis of CVD coded in any of 17 diagnostic fields or a code for a cardiovascular procedure in any of 12 procedure fields. The total number of hospital admissions relating to these patients (for any cause) was 3771819 and the total number of deaths was 130294 . From this we selected the records of all admissions for CABG and PCI procedures as defined below.

\section{ICD code definitions for $C A B G, P C I$, and $P C I$ with stenting procedures}

For the period 1979-87, procedures were coded with the International classification of procedures in medicine. ${ }^{14}$ The relevant codes for CABG procedure were 5-361 and 5-362 and for PCI procedures, 5-363. From 1988 to mid-1999, procedures were coded according to the procedure classification associated with ICD-9, clinical modification (ICD-9-CM). ${ }^{15}$ The relevant codes for this period were 36.10 to 36.19 for CABG, 36.01 to 36.05 for PCI, and 36.06 and 36.07 for PCI with coronary stents. From mid-1999, procedures were coded with the Australian classification of health interventions tabular list of procedures (ICD-10, Australian modification) ${ }^{16}$ mapped to ICD-9-CM.

\section{Identification of first CARPs}

All admission records that contained procedure codes corresponding to $\mathrm{CABG}, \mathrm{PCI}$, or coronary stenting procedures were identified and abstracted from the linked database for analysis and then sorted by unique identifier and the date of hospital admission. Consequently, for each patient, the first record appearing would correspond to their first or index CARP and their second record (if any) would correspond to their second or repeat CARP. After this, a summary record was created that contained the date of admission for the first CARP procedure, the date of admission for the second CARP procedure (if any), and the date and cause of death (if this had occurred).

\section{Statistical methods}

All patients having a first (index) CARP between 1980 and 2001 were included in the analysis. The date of censoring was 31 December 2001. The events of interest were repeat CARP or death from CVD after the index CARP. If a person died of causes other than CVD, then their survival was treated as censored. CVD deaths were defined as any death coded between 390 and 459 (ICD-9) or I00 and I99 (ICD-10).

For each of our events of interest, time to repeat CARP and time to death from CVD, we computed Kaplan-Meier estimates of the unadjusted absolute risk of the event occurring at 28 days, one year, and two years. These were computed separately for index CABG and PCI procedures for the periods 1980-4, 1985-9, 1990-4, 1995-9, and 2000-1.

We used Cox proportional hazards regression ${ }^{17}$ to estimate the two year relative risk of repeat CARP or of death from CVD both with and without adjustment for the effects of sex, age at index CARP (35-79 years in five year age groups and $\geqslant 80$ ), rural area (Perth metropolitan area versus rural area), and history of acute myocardial infarction (AMI). History of AMI was defined as an admission to hospital for AMI within 90 days before the index CARP. Relative risks were estimated within the time periods given above with the 1985-9 period used as the reference. This period was used as the reference period because the earlier period, 1980-4, was a period when PCI procedures were first introduced and therefore outcomes in this period may not reflect outcomes in the later periods when the procedure was more established. To test the hypothesis that there was no trend in the two year risk of repeat CARP or of death from CVD, year of index admission was entered into the Cox model as a continuous variable and the model was restricted to the time interval 1985-2001. For this analysis censoring was at two years after the initial CARP or 31 December 2001, whichever occurred first.

\section{RESULTS}

The characteristics of patients who received CARPs for the first time changed significantly over the period 1980-2001. There was a steady increase in both the mean and standard deviation of age (table 1). One implication of this can be seen clearly in the proportion of patients who were aged 75 years or more. In 1980-4, these patients accounted for only $1.9 \%$ of patients having a first CARP procedure, whereas by 2000-1 they represented $17.8 \%$ of patients. Both CABG and PCI procedures increased in this age group. In contrast, the proportion of female patients and the metropolitan-rural mix of patients changed only marginally over this period.

Both CABG and PCI procedures have been used to treat patients admitted with an AMI or with a history of admission for AMI in the previous 90 days. The proportion of such patients increased over the period 1980-2001, particularly for patients admitted with an AMI and treated by PCI $(30 \%$ of patient in 2000-1 compared with $13.6 \%$ of patients in 1980-4).

PCI accounted for only $8.6 \%$ of CARPs performed in 1980-4 but this had grown to $64.0 \%$ by $2000-1$. Coronary artery stenting with PCI was introduced in 1995 and was performed in $65 \%$ of PCI cases in 1995-9 and $90.7 \%$ in 2000-1.

Table 2 shows the results of the Kaplan-Meier analysis for absolute risks. If we consider first the results for repeat CARP, it is immediately obvious that the risk of a repeat CARP was much higher after a PCI procedure than after CABG. For example, in the periods 1980-4 and 1985-9, the risk of a repeat CARP within two years after a PCI procedure was over $30 \%$. Most of these repeat procedures occurred in the first year after the PCI procedure. In contrast, less than $2 \%$ of CABG procedures had resulted in a repeat CARP within two years. Since 1989, however, the risk of a repeat CARP after a PCI declined substantially so that, by 2000-1, the two year risk was $12.4 \%$. Most of this decline occurred among repeat CARPS performed during the first year after the index PCI. There is also evidence of a decline after 1994 in the risk of repeat CARP after a CABG procedure.

When we consider the risk of death from CVD after an index CABG or PCI procedure (table 2), we can see that in the first two time periods (1980-4 and 1985-9) the risks were similar for both CABG and PCI, with the risk after CABG in 1985-9 being slightly higher. It is also apparent that the 28 day risk of death from CVD was higher after a CABG procedure than after a PCI. This may reflect postoperative mortality as well as case-mix selection effects. After 1989, while the risk of CVD death after a CABG procedure was more than double the risk after a PCI procedure, the risk of CVD death appears reasonably constant from 1990 through to 2001.

If we consider PCI and CABG procedures combined, then there appears to be little difference between the risk of CVD death after CARPs performed in 1980-4 and the risk after CARPS performed in 2000-1.

These are, however, crude estimates of risk and therefore trends in the risk of repeat CARP or death from CVD since 1985 may be masked by changes in the demographic profile 
Table 1 Baseline characteristics of patients receiving first CARPs between 1980 and 2001

\begin{tabular}{|c|c|c|c|c|c|}
\hline & $1980-4$ & $1985-9$ & $1990-4$ & 1995-9 & $2000-1$ \\
\hline Number of procedures & 3014 & 4811 & 8271 & 10460 & 4535 \\
\hline \multicolumn{6}{|l|}{ All procedures } \\
\hline Mean (SD) age (years) & 57.71 (8.85) & $60.21(9.44)$ & $61.75(10.12)$ & $62.79(10.73)$ & $63.22(11.15)$ \\
\hline Aged $\geqslant 75(\%)$ & 1.92 & 5.36 & 9.24 & 14.25 & 17.77 \\
\hline Women (\%) & 18.71 & 22.84 & 24.69 & 24.38 & 24.92 \\
\hline $\mathrm{PCl}$ without stents (\%) & 8.56 & 36.98 & 41.12 & 19.44 & 5.95 \\
\hline $\mathrm{PCl}$ with stents (\%) & 0.00 & 0.00 & 0.00 & 35.90 & 58.02 \\
\hline Rural area (\%) & 20.6 & 21.24 & 22.76 & 22.27 & 22.6 \\
\hline \multicolumn{6}{|l|}{ CABG procedures } \\
\hline Mean (SD) age (years) & $57.89(8.82)$ & $61.67(9.09)$ & $63.49(9.60)$ & 64.24 (9.97) & $64.96(10.21)$ \\
\hline Aged $\geqslant 75(\%)$ & 2.02 & 6.81 & 11.19 & 15.18 & 19.30 \\
\hline Women (\%) & 18.13 & 21.93 & 23.42 & 23.23 & 22.40 \\
\hline MI on admission (\%) & 7.34 & 7.88 & 9.17 & 10.56 & 11.48 \\
\hline $\mathrm{MI}$ admission in previous 90 days (\%) & 5.50 & 8.99 & 7.75 & 8.85 & 10.19 \\
\hline \multicolumn{6}{|l|}{$\mathrm{PCl}$ procedures } \\
\hline Mean (SD) age (years) & $56.07(8.89)$ & $57.65(9.47)$ & $59.22(10.33)$ & $61.38(11.25)$ & $62.08(11.57)$ \\
\hline Aged $\geqslant 75(\%)$ & 0.78 & 2.75 & 6.41 & 13.31 & 16.71 \\
\hline Women $(\%)$ & 25.58 & 24.45 & 26.76 & 25.51 & 26.53 \\
\hline Ml on admission (\%) & 13.57 & 21.47 & 19.85 & 16.84 & 30.00 \\
\hline Ml admission in previous 90 days (\%) & 4.65 & 8.38 & 8.97 & 12.11 & 11.73 \\
\hline
\end{tabular}

$\mathrm{CABG}$, coronary artery bypass grafting; CARPs, coronary artery revascularisation procedures; $\mathrm{MI}$, myocardial infarction; $\mathrm{PCl}$, percutaneous coronary intervention.

of patients across this period. To adjust for the confounding effects of age, sex, place of residence, and the patient's prior history of myocardial infarction, a series of proportional hazard regression models were used.

In table 3, the unadjusted relative risk is the risk of the event occurring within two years of the index procedure relative to that risk in 1985-9. The $\mathrm{p}$ value tests the hypothesis of no trend in relative risk from 1985 to 2001. These unadjusted results therefore correspond to the comparison of the two year absolute risks in table 2. There was no evidence of a trend in the unadjusted relative risk of repeat CARP after a CABG procedure $(\mathrm{p}=0.84)$, whereas there was a highly significant trend associated with PCI procedures performed since 1985 ( $p<0.001)$. After adjustment for age, sex, place of normal residence, and prior myocardial infarction, the trend in the relative risk of repeat CARP after a CABG procedure remained non-significant. The significant decline in the relative risk of repeat CARP after a PCI procedure remained after multivariate adjustment.

With regard to the risk of death from CVD, there was evidence of a trend in the unadjusted relative risks after a
CABG procedure $(\mathrm{p}=0.04)$ but not after a PCI procedure $(p=0.59)$. After adjustment for age, sex, rural area, and prior myocardial infarction, however, a trend towards reduced risk of death from CVD after both CABG and PCI procedures was apparent $(\mathrm{p}<0.001)$. For both procedures, the major part of the decline in multivariate adjusted risk of death from CVD occurred from 1985 to 1994. Overall, the multivariate adjusted risk of death from CVD after CARPs decreased by about 50\% from 1985-9 to 2000-1 ( $p<0.001$ ).

\section{DISCUSSION}

The goal of our study was to evaluate temporal changes in the risk of death from coronary heart disease and in the risk of repeat revascularisation in a population based cohort of patients treated with coronary artery revascularisation in Western Australia between 1980 and 2001.

While we observed little change in the two year risk of repeat revascularisation among patients who had initially received a CABG, we found substantial reductions among PCI patients. Virtually all of this improvement occurred within one year of the initial procedure. When we examined the two

Table 2 Absolute risk in percentage of repeat CARP or cardiovascular disease death at 28 days, one year, and two years after $\mathrm{CABG}$ or $\mathrm{PCl}$, at one year conditional on 28 day survival, and at two years conditional on one year survival

\begin{tabular}{|c|c|c|c|c|c|c|}
\hline & & $1980-4$ & $1985-9$ & $1990-4$ & $1995-9$ & 2000-1 \\
\hline \multicolumn{7}{|c|}{ Repeat CARP } \\
\hline \multirow{3}{*}{ CABG } & 28 days & 0.51 & 0.16 & 0.08 & 0.08 & 0.00 \\
\hline & 1 year & 1.54 & 0.94 & 0.77 & 1.00 & 0.84 \\
\hline & 2 years & 1.92 & 1.39 & 1.52 & 1.49 & 1.18 \\
\hline \multirow[t]{3}{*}{$\mathrm{PCl}$} & 28 days & 1.72 & 2.62 & 3.11 & 2.39 & 1.85 \\
\hline & 1 year & 27.74 & 29.59 & 25.91 & 16.25 & 11.38 \\
\hline & 2 years & 31.24 & 33.64 & 29.16 & 18.43 & 12.35 \\
\hline \multicolumn{7}{|c|}{ Cardiovascular disease death } \\
\hline \multirow[t]{3}{*}{ CABG } & 28 days & 1.80 & 2.40 & 2.18 & 2.78 & 2.20 \\
\hline & 1 year & 3.02 & 4.22 & 3.74 & 3.85 & 3.64 \\
\hline & 2 years & 3.93 & 5.47 & 4.44 & 4.48 & 4.94 \\
\hline \multirow[t]{3}{*}{$\mathrm{PCl}$} & 28 days & 0.85 & 0.93 & 0.21 & 0.99 & 0.80 \\
\hline & 1 year & 2.14 & 2.32 & 0.88 & 1.69 & 1.76 \\
\hline & 2 years & 3.42 & 3.25 & 1.39 & 2.15 & 2.06 \\
\hline \multirow[t]{3}{*}{ CARP } & 28 days & 1.73 & 1.87 & 1.39 & 1.88 & 1.35 \\
\hline & 1 year & 2.95 & 3.54 & 2.59 & 2.76 & 2.50 \\
\hline & 2 years & 3.89 & 4.67 & 3.21 & 3.30 & 3.21 \\
\hline
\end{tabular}


Table 3 Relative risk across calendar year of repeat CARP and for cardiovascular disease death in the two years after initial $\mathrm{CABG}$ or $\mathrm{PCl}$ procedure

\begin{tabular}{|c|c|c|}
\hline Period & Unadjusted RR & Adjusted* RR $(95 \% \mathrm{Cl})$ \\
\hline \multicolumn{3}{|c|}{$\begin{array}{l}\text { Repeat CARP } \\
\text { CABG }\end{array}$} \\
\hline $1980-4$ & 1.40 & $1.32(0.87$ to 1.99$)$ \\
\hline 1985-9 & 1.00 & 1.00 \\
\hline $1990-4$ & 1.09 & $1.13(0.77$ to 1.66$)$ \\
\hline 1995-9 & 1.08 & $1.16(0.79$ to 1.70$)$ \\
\hline $2000-1$ & 0.83 & $0.90(0.47$ to 1.72$)$ \\
\hline $\mathrm{p}$ Valuet & 0.844 & 0.559 \\
\hline \multicolumn{3}{|l|}{$\mathrm{PCl}$} \\
\hline $1980-4$ & 0.92 & $0.88(0.69$ to 1.13$)$ \\
\hline $1985-9$ & 1.00 & 1.00 \\
\hline $1990-4$ & 0.86 & 0.87 (0.79 to 0.97$)$ \\
\hline 1995-9 & 0.51 & 0.53 (0.48 to 0.59$)$ \\
\hline $2000-1$ & 0.34 & $0.36(0.31$ to 0.41$)$ \\
\hline $\mathrm{p}$ Value & $<0.001$ & $<0.001$ \\
\hline \multicolumn{3}{|c|}{ Cardiovascular disease death } \\
\hline \multicolumn{3}{|c|}{ CABG } \\
\hline $1980-4$ & 0.71 & $0.93(0.73$ to 1.20$)$ \\
\hline $1985-9$ & 1.00 & 1.00 \\
\hline $1990-4$ & 0.81 & 0.71 (0.58 to 0.86$)$ \\
\hline $1995-9$ & 0.82 & $0.65(0.53$ to 0.80$)$ \\
\hline $2000-1$ & 0.84 & $0.62(0.47$ to 0.84$)$ \\
\hline $\mathrm{p}$ Value & 0.043 & $<0.001$ \\
\hline \multicolumn{3}{|l|}{$\mathrm{PCl}$} \\
\hline $1980-4$ & 1.05 & $1.44(0.69$ to 3.04$)$ \\
\hline $1985-9$ & 1.00 & 1.00 \\
\hline $1990-4$ & 0.42 & $0.37(0.25$ to 0.55$)$ \\
\hline 1995-9 & 0.66 & $0.43(0.31$ to 0.60$)$ \\
\hline $2000-1$ & 0.71 & $0.42(0.28$ to 0.63$)$ \\
\hline $\mathrm{p}$ Value & 0.594 & $<0.001$ \\
\hline \multicolumn{3}{|l|}{ CARP } \\
\hline $1980-4$ & 0.83 & 1.05 (0.84 to 1.32$)$ \\
\hline $1985-9$ & 1.00 & 1.00 \\
\hline $1990-4$ & 0.68 & $0.60(0.50$ to 0.71$)$ \\
\hline $1995-9$ & 0.71 & $0.53(0.44$ to 0.63$)$ \\
\hline 2000-1 & 0.67 & $0.47(0.37$ to 0.59$)$ \\
\hline $\mathrm{p}$ Value & $<0.001$ & $<0.001$ \\
\hline
\end{tabular}

*Adjusted for age, sex, rural area, and prior infarct (acute myocardial infarction); $t p$ value is test for trend over the period 1985-2001. $\mathrm{Cl}$, confidence interval; $\mathrm{RR}$, relative risk.

year risk of death from CVD, we found relatively modest improvement for CABG patients and PCI patients. After multivariate adjustment for age, sex, and place of residence, however, large and significant reductions in the risk of death from CVD were observed for both CABG and PCI patients. These changes in risk occurred across a period when patients receiving CARPs were increasingly older and more likely to be admitted with AMI.

The risk of repeat revascularisation among PCI patients in our study was highest in the 1985-9 period, when the risk at one year was $29.6 \%$. This is comparable with the levels of one year risk estimated in CABRI (coronary angioplasty versus bypass revascularisation investigation $)^{6}(33.6 \%)$ and RITA (randomised intervention treatment of angina) $)^{5}(24 \%)$ but less than that observed in GABI (German angioplasty bypass surgery investigation $)^{3}(44 \%)$.

Although findings from observational studies should be generalised with some caution, our study suggests that recent advances in coronary revascularisation techniques such as the use of internal mammary grafts ${ }^{18}$ and the introduction of coronary stents after 1995 have contributed to the reduced risk of death from coronary artery disease and risk of repeat revascularisation.

Our study, however, does have certain limitations. ICD coding of procedures does not identify the artery or arteries that have been treated. Thus, while we can identify repeat revascularisations, we do not know whether they are revascularisations of previously treated arteries (target vessel revascularisations) or revascularisations of previously untreated arteries (non-target vessel revascularisations). If repeat revascularisations were predominantly target vessel revascularisations then the reduction in the risk of repeat revascularisation would indicate true reduction in the rate of restenosis or reduction in the recurrence of symptoms because of improved medical treatment despite restenosis. If, on the other hand, repeat revascularisations were predominantly non-target vessel revascularisations the reduction in the risk of repeat revascularisation would indicate reduction in the rate of progression of arterial disease or an increase in multiple vessel PCI treatments performed in one admission rather than staged over a number of admissions.

Because we do not have data on the medical management of patients in our study we cannot definitively apportion the reductions in risk of death or repeat revascularisation that we observed between changes in revascularisation methods and changes in medical treatment. The increasing use of aspirin,, ${ }^{19}$ the introduction of treatment with antiplatelet, ${ }^{20}$ and the increasing use of lipid lowering drugs would all have contributed to the reductions in risk we have observed in our study. For example, the Perth monitoring trends and determinants in cardiovascular disease (MONICA) project showed a rapid increase in patients with AMI prescribed aspirin at discharge (from $28.6 \%$ in 1985 to $90.4 \%$ in $1988-$ 90), while a further study of AMI in 1998 found major increases since 1991-93 in patients prescribed angiotensin converting enzyme (ACE) inhibitors (from 5\% to 40\%) and lipid lowering drugs (from less than 5\% to 60\%) at discharge. These changes are mirrored by rapid increases in prescriptions for ACE inhibitors and lipid lowering drugs under the Australian National Pharmaceutical Benefit Scheme. ${ }^{21}$

We are conducting a more detailed study in which data describing the CABG and PCI procedures and the medication prescribed are being abstracted from patient case notes. When completed, this study will be able to address these issues.

Population based studies such as ours provide testimony to what is seen in randomised controlled trials. Our results are reassuring because, while the evidence suggests that patients being treated by coronary artery revascularisation are becoming more severely ill, there is still evidence of improving outcomes.

\section{ACKNOWLEDGEMENTS}

We are grateful for help with the preparation of data files used for this study, which was provided by Mr Steve Ridout from the Unit of Clinical Epidemiology within the School of Population Health and by Ms Di Rosman and staff at the Data Linkage Unit. The Unit of Clinical Epidemiology is supported by a grant from the Western Australian Department of Health. This study was funded by a grant from the National Health and Medical Research Council (project grant number 139100).

The sponsors of the study had no role in the study design, data collection, data analysis, data interpretation, writing of the report, or the decision to submit the paper for publication.

\section{Authors' affiliations}

K A McCaul, M S T Hobbs, M W Knuiman, School of Population Health, University of Western Australia, Crawley, Western Australia, Australia J M Rankin, Department of Cardiology, Royal Perth Hospital, Perth, Western Australia

I Gilfillan, Cardiothoracic Surgery Unit, Fremantle Hospital, Fremantle, Western Australia

\section{REFERENCES}

1 Hobbs MST, McCaul KA, Knuiman MW, et al. Trends in coronary artery revascularisation procedures in Western Australia, 1980-2001. Heart 2004;90:1036-41.

2 Anon. BARI Investigators. Comparison of coronary bypass surgery with angioplasty in patients with multivessel disease. The bypass angioplasty 
revascularization investigation (BARI) investigators. N Engl J Med 1996;335:217-25.

3 Hamm CW, Reimers J, Ischinger T, et al. A randomized study of coronary angioplasty compared with bypass surgery in patients with symptomatic multivessel coronary disease. German angioplasty bypass surgery investigation (GABI). N Engl J Med 1994;331:1037-43.

4 King SB 3rd, Lembo NJ, Weintraub WS, et al. randomized trial comparing coronary angioplasty with coronary bypass surgery. Emory angioplasty versus surgery trial (EAST). N Engl J Med 1994;331:1044-50.

5 Anon. Coronary angioplasty versus coronary artery bypass surgery: the randomized intervention treatment of angina (RITA) trial. RITA trial participants. Lancet 1993;341:573-80.

6 CABRI Trial Participants. First-year results of CABRI (coronary angioplasty versus bypass revascularisation investigation). CABRI trial participants. Lancet 1995; 346:1 179-84.

7 Rodriguez A, Mele E, Peyregne E, et al. Three-year follow-up of the Argentine randomized trial of percutaneous transluminal coronary angioplasty versus coronary artery bypass surgery in multivessel disease (ERACI). J Am Coll Cardiol 1996;27:1178-84.

8 Fischman DL, Leon MB, Baim DS, et al. A randomized comparison of coronary-stent placement and balloon angioplasty in the treatment of coronary artery disease. Stent restenosis study investigators. N Engl J Med 1994;331:496-501.

9 Serruys PW, de Jaegere P, Kiemeneii F, et al. A comparison of balloonexpandable-stent implantation with balloon angioplasty in patients with coronary artery disease. BENESTENT study group. N Engl J Med 1994;331:489-95.

10 Savage MP, Douglas JS Jr, Fischman DL, et al. Stent placement compared with balloon angioplasty for obstructed coronary bypass grafts. Saphenous vein de novo trial investigators. N Engl J Med 1997;337:740-7.
11 Sirnes PA, Golf S, Myreng Y, et al. Stenting in chronic coronary occlusion (SICCO): a randomized, controlled trial of adding stent implantation after successful angioplasty. J Am Coll Cardiol 1996;28:1444-51.

12 Versaci F, Gaspardone A, Tomai F, et al. A comparison of coronary-artery stenting with angioplasty for isolated stenosis of the proximal left anterior descending coronary artery. N Engl J Med 1997;336:817-22.

13 Holman CD, Bass AJ, Rouse IL, et al. Population-based linkage of health records in Western Australia: development of a health services research linked database. Aust N Z J Public Health 1999;23:453-9.

14 World Health Organization. International classification of procedures in medicine. Geneva: WHO, 1978

15 Commission on Professional and Hospital Activities. International classification of diseases, 9th revision, clinical modification: ICD-9CM: vol 3. Procedures-tabular list and alphabetic index. Annoted ed. Ann Arbour, Michigan: Commission on Professional and Hospital Activities; 1987.

16 National Centre for Classification in Health. Tabular list of procedures ICD10-AM. Australian classification of health interventions (ACHI). Sydney: National Centre for Classification in Health, 2002.

17 Cox DR. Regression models and life tables (with discussion). J R Stat Soc B 1972;34:187-220.

18 Loop FD, Lytle BW, Cosgrove DM, et al. Influence of the internal-mammary artery graft on 10-year survival and other cardiac events. N Engl J Med 1986;314:1-6.

19 Schwartz L, Bourassa MG, Lesperance J, et al. Aspirin and dipyridamole in the prevention of restenosis after percutaneous transluminal coronary angioplasty. N Engl J Med 1988;318:1714-9.

20 The EPIC Investigators. Use of a monoclonal antibody directed against the platelet glycoprotein Ilb/llla receptor in high-risk coronary angioplasty. The EPIC investigators. N Engl J Med 1994;330:956-61.

21 Mathur S. Epidemic of coronary heart disease and its treatment in Australia. Canberra: Australian Institute of Health and Welfare, 2002

\section{IMAGES IN CARDIOLOGY}

\section{Ultrastructure of transplanted mesenchymal stem cells after acute myocardial infarction}

M esenchymal stem cells (MSCs) were isolated from sheep bone marrow and expanded in vitro for four weeks. Cells were found to be CD34 (-) negative by flow cytometry. The bone marrow derived MSCs (BD-MSCs) were implanted in the border zone of the infarcted area, four hours after occlusion of the first obtuse marginal branch of the circumflex artery. One month later, the animal was killed and the transplanted BD-MSCs examined by transmission electron microscopy.

The figure shows a high power electron micrograph of a longitudinal section through two muscle fibres. The viable myocardium on the left shows a normal appearance of the sarcomeres. Note disruption of myofibrils in the infarcted area on the right. Mitochondria appear small and spherical. The arrow points to a cell that fulfils the ultrastructural criteria of satellite cells and is morphologically identical with satellite cells described in skeletal muscle. The satellite cell sends cytoplasmic extensions into the adjacent muscle fibre, enabling the plasma membrane to make close contact. Note the continuous basal lamina surrounding the satellite cell and myofibre. The abundance of heterochromatin, paucity of cytoplasmic organelles and high nuclear/cytoplasmic volume ratio is indicative of a relatively inactive satellite cell. Immunohistochemical staining for troponin I and cardiac specific myosin of the implanted BD-MSCs was negative.

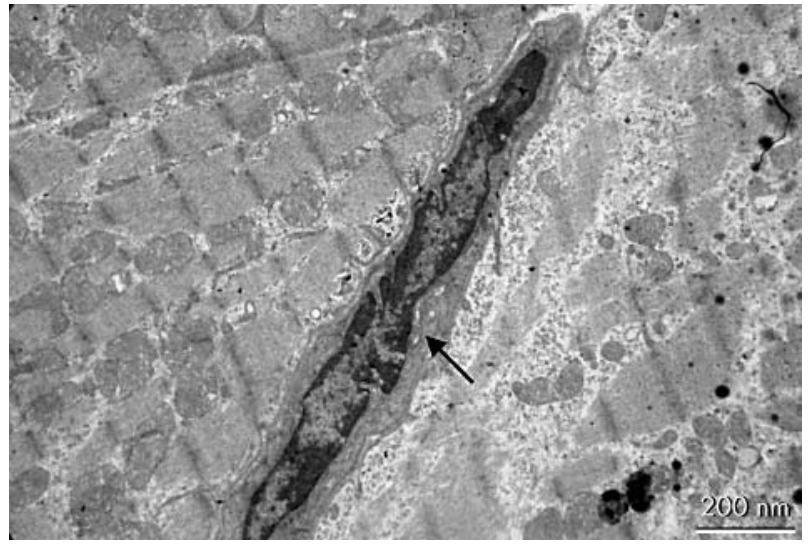

M Thoelen

$F$ Vandenabeele

J L Rummens

M Hendrikx

mieke.thoelen@luc.ac.be 